We present a patient who developed the Lambert-Eaton myasthenic syndrome (LEMS) in association with systemic lupus erythematosus (SLE). Severe proximal weakness with electrodiagnostic evidence of LEMS developed over 2 days during an exacerbation of cutaneous manifestations (bullous pemphigoid) associated with SLE. Following an increase in the daily dose of prednisone, there was complete clinical restitution of strength within 2 weeks and a slower resolution of electrodiagnostic abnormalities over 6 months. Marked serologic abnormalities were present at the onset and showed improvement over 6-8 months. LEMS had been infrequently described in association with SLE. The immunologic features of both SLE and LEMS suggest a linkage between the two diseases in this patient. We hypothesize that increased antibodies associated with exacerbation of SLE cross reacted with the neuromuscular junction membrane to produce LEMS.

MUSCLE \& NERVE 12:15-19

1989

\title{
TRANSIENT LAMBERT-EATON MYASTHENIC SYNDROME ASSOCIATED WITH SYSTEMIC LUPUS ERYTHEMATOSUS
}

MARK B. BROMBERG, MD, PhD, JAMES W. ALBERS, MD, PhD, and $W$. JOSEPH McCUNE, MD

There is growing evidence that the LambertEaton myasthenic syndrome (LEMS) ${ }^{4,13}$ is an autoimmune disease. ${ }^{14}$ Passive transfer of the disorder has been demonstrated in suitably prepared mice by injection of the IgG component of serum from affected patients. ${ }^{2,11,14,15}$ Transfer is not related to the presence of an underlying tumor. ${ }^{14}$ The antigenic target is unknown, but protein complexes in the active zone of the presynaptic membrane, possibly associated with calcium channels, have been hypothesized. ${ }^{5}$ Patients with LEMS, with or without neoplasm, have shown improvement with immunosuppressive therapies, including combinations of prednisone and azothioprine, and with therapeutic plasma exchange. ${ }^{20,24,27}$ In addition to neoplasms, LEMS has also been associated with autoimmune disorders. ${ }^{6,17}$ There is a

From the Departments of Neurology (Drs. Bromberg and Albers) and Internal Medicine (Dr. McCune), University of Michigan, Ann Arbor, MI

Presented in part at the 33rd Annual Meeting of the American Association of Electromyography and Electrodiagnosis, Boston, MA, September $25-27,1986$.

Address reprint requests to Dr. Bromberg at the Department of Neurology, University of Michigan Medical Center, 1920/0316 Taubman Center, 1500 East Medical Center Drive. Ann Arbor, Ml 48109-0316.

Accepted for publication January 11, 1988

$0148-639 \times / 1201 / 0015 \$ 04.00 / 5$

C) 1989 John Wiley \& Sons, Inc. higher-than-expected association of organ-specific autoantibodies (antithyroid, antiparietal cell, antiacctylcholine receptor) than non-organ-specific autoantibodies (Rheumatoid factor, antinuclear antibody) in patients with LEMS. ${ }^{17}$ Consequently, LEMS is more frequently associated with thyroiditis and pernicious anemia than with SLE, Sjogrens syndrome, rheumatoid arthritis, or progressive systemic sclerosis, and only one case of LEMS has been reported in a patient with SLE. ${ }^{8}$ Of note, myasthenia gravis is common to both organspecific and non-organ-specific groups, and there are reports of electrophysiologic findings of both myasthenia gravis and LEMS in the same patient. ${ }^{21}$

The clinical picture of LEMS is chronic progressive weakness, measured over months to years, involving proximal muscles more than distal muscles, but usually sparing bulbar muscles. ${ }^{20}$ The usual therapeutic response to immunosuppression is slow, with objective clinical improvement commencing from 14 days to 3 months after initiation of therapy. ${ }^{24}$ We present a patient with transient symptoms and signs of LEMS occurring concomitantly with an exacerbation of SLE. The association of these two conditions suggests that the transient LEMS may have been a component of a more generalized autoimmune disorder, likely related to either formation of multiple au- 


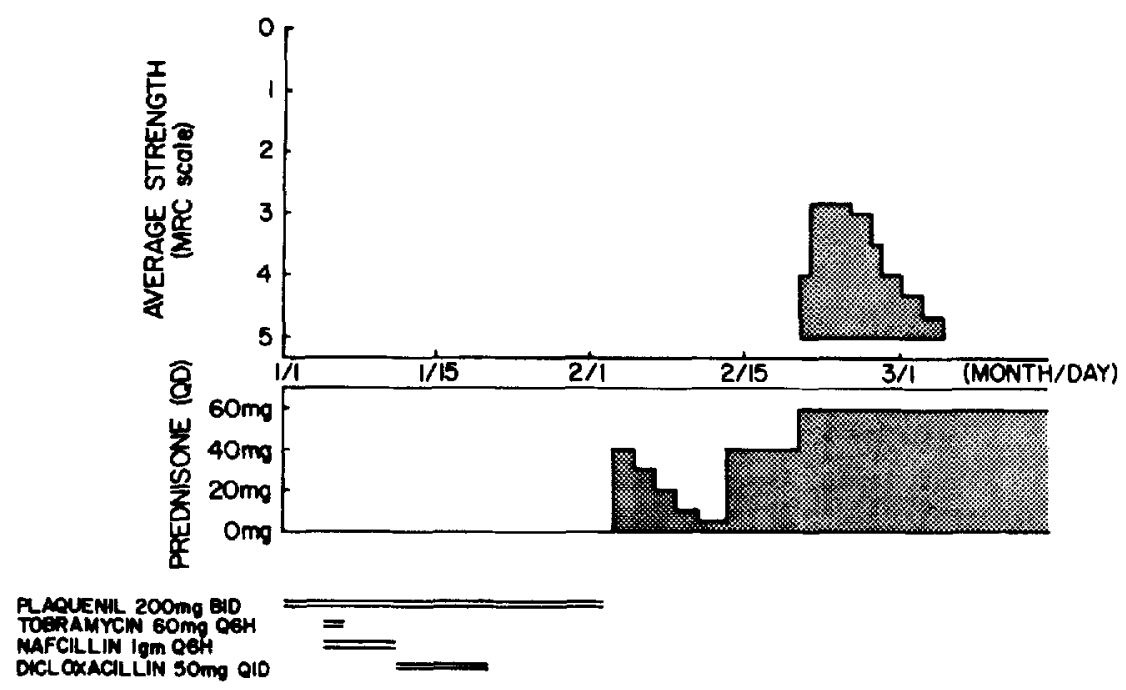

FIGURE 1. Temporal relationship between strength (MRC scale, $5=$ normal; upper graph), prednisone dosage (middle graph), and other medications (lower graph).

toantibodies with different specificities or autoantibodies capable of cross reacting with different antigens.

\section{Case presentation}

The patient was a 21-year-old black female with SLE for 5 years. She fulfilled 8 of 11 ARA criteria for $\operatorname{SLE}^{25}$ (Table 1), and her disease was characterized by discoid lupus and bullous pemphigoid lesions. She had no known previous central or peripheral nervous system involvement. During the 4-6 weeks prior to onset of weakness, she was treated with Nafcillin, Tobramycin, and Doxicycillin for minor toe and scalp infections (Fig. 1). Five weeks prior to onset of weakness she was placed on hydroxychloroquine (200 $\mathrm{mg} \mathrm{qD}$ ) for I month for a flare of her bullous phemphigoid. Because of continuing skin eruptions and pruritus, hy-

\begin{tabular}{clr}
\hline Table 1. Systemic lupus erythematosus classification criteria. \\
\hline 1 & Malar rash & - \\
2 & Discoid rash & + \\
3 & Photosensitivity & + \\
4 & Oral uicers & + \\
5 & Arthritis & + \\
6 & Serositis (pleuropericarditis) & + \\
7 & Renal disorders & - \\
8 & Neurologic disorder & + \\
9 & Hematologic disorder (leukopenia) & + \\
10 & Immunologic disorder (positive anti-DNA) & + \\
11 & Antinuclear antibody & + \\
\hline
\end{tabular}

Source: Ref. 25.

Note: + indicates presence of clinical features in patient, - indicates absence of clinical features in patient. droxychloroquine was discontinued and a burst of prednisone was instituted, starting at $40 \mathrm{mg} \mathrm{qD}$ and tapering to zero over 10 days. At the end of the burst, prednisone was restarted at $40 \mathrm{mg} \mathrm{qD}$ because of persistent skin lesions. Her weakness began 1 week later with marked proximal weakness progressing over 2 days. She was unable to elevate her arms against gravity, rise from bed, or walk without assistance. Muscle stretch reflexes, originally normal, became hypoactive and then absent. Pupillary function was normal, and there were no other signs of cholinergic blockade. At onset of weakness, prednisone was increased to 60 $\mathrm{mg} \mathrm{qD}$ and maintained for several months. She experienced an improvement in strength within 4 days of dose change and was clinically normal within 2 weeks. She has remained strong without evidence of a neoplasm after 48 months of followup.

Electrodiagnostic studies were performed serially after onset of weakness (Table 2). During maximum weakness all compound muscle action potential (CMAP) amplitudes were reduced. There was up to a $30 \%$ decrement at low frequency repetitive stimulation $(2 \mathrm{~Hz}$ supramaximal stimulation; Fig. 2A) and up to $300 \%$ facilitation at high frequency stimulation $(50 \mathrm{~Hz}$ supramaximal stimulation; Fig. 2B) or immediately after 5 seconds of maximal voluntary exercise (Fig. 2A). All electrodiagnostic abnormalities resolved over 6 months (Fig. 3) with restoration of CMAP amplitude and decreased decrement and facilitation to normal values (Fig. $2 \mathrm{C}$ ).

At the time of maximum weakness, serum po- 
Table 2. Sensory and motor nerve evoked responses.

\begin{tabular}{|c|c|c|c|c|c|}
\hline \multirow[b]{2}{*}{ Test } & \multicolumn{4}{|c|}{ Date } & \multirow[b]{2}{*}{ Normal values } \\
\hline & $2 / 21$ & $3 / 2$ & $6 / 14$ & $8 / 23$ & \\
\hline \multicolumn{6}{|l|}{ Sural nerve } \\
\hline Amplitude $(\mu \mathrm{V})$ & 20 & NA & NA & 20 & $>6$ \\
\hline \multicolumn{6}{|l|}{ Ulnar motor nerve } \\
\hline Amplitude (mV) & 2.0 & 1.8 & 7.0 & 8.0 & $6-16$ \\
\hline Decrement at $2 \mathrm{~Hz}(\%)$ & 30 & 25 & 10 & 0 & None \\
\hline Facilitation with exercise (\%) & 300 & 300 & 50 & 30 & $<50$ \\
\hline Distal latency (msec) & 3.2 & 2.6 & 2.6 & 2.7 & $1.8-3.5$ \\
\hline \multicolumn{6}{|l|}{ Single fiber EMG } \\
\hline Extensor digitorum communis muscle jitter ( $\mu \mathrm{sec}$ ) & NA & NA & NA & 41 & $16-33$ \\
\hline
\end{tabular}

Note: $N A=$ not available.

tassium, magnesium, calcium, and thyroid function tests were normal. Antiacetylcholine receptor autoantibody titers were undetectable. The hematocrit was 28.8 with microcytic indices. Total hemolytic complement, C3, and C4 were depressed (Table 3). The Raji Cell assay, ANA, and antiDNA (Farr assay) were elevated. Immunofluorescent staining of a skin biopsy showed positive ANA deposition. Over the next 6 months the complement and autoantibodies abnormalities improved (Table 3).

\section{DISCussion}

This patient fulfilled the clinical and electrodiagnostic criteria for LEMS; proximal weakness sparing bulbar muscles, low CMAP amplitude, decremental response at low stimulus rates, and abnormal facilitation at high stimulation rates or after exercise. ${ }^{9}$ Her clinical course is unique, with subacute onset and rapid resolution of weakness.
There were no serum electrolyte abnormalities associated with the weakness and no evidence for myasthenia gravis. A pharmacologically induced neuromuscular transmission defect was unlikely. There was no evidence that unintended medications were administered. Chloroquine, an analogue of hydroxychloroquine, has been associated with postoperative respiratory depression, and there is evidence that it acts postsynaptically. ${ }^{10,26}$ Less is known about hydroxychloroquine. Our patient received no hydroxychloroquine during the 2 weeks prior to onset of weakness. After ingestion, the clinical half-life of hydroxychloroquine is $50-56$ hours, with the majority excreted with a half-life of 3 days while the remainder of the drug is excreted more slowly. ${ }^{18}$ Additionally, our patient had taken hydroxychloroquine at an earlier time and has been on chloroquine since, without weakness. She also had taken a 2 day course of an aminoglycoside antibiotic, Tobramycin, 2 months

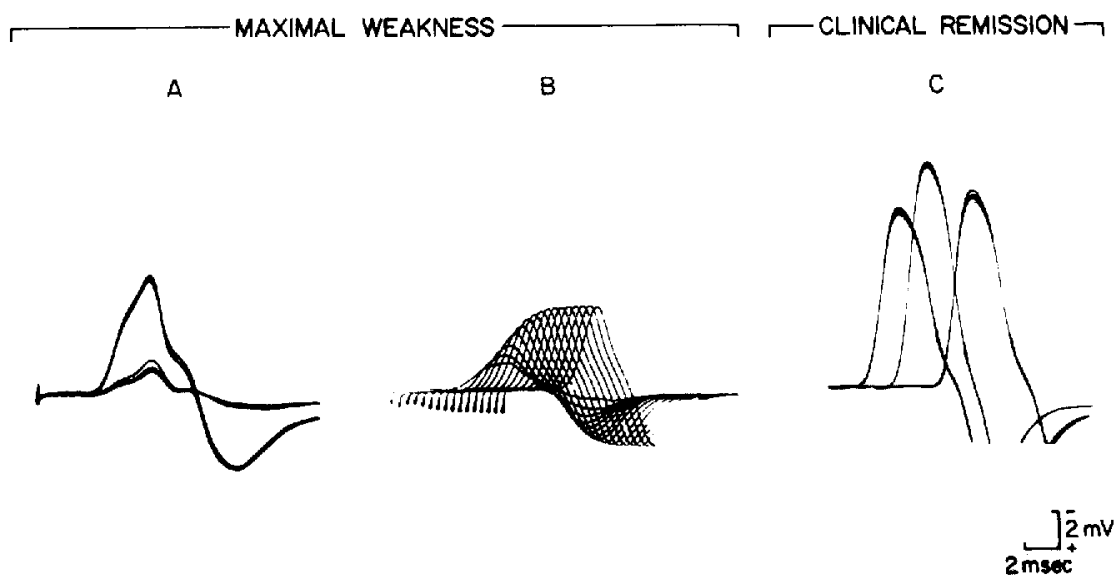

FIGURE 2. Compound muscle action potentials (recorded from hypothenar muscles) to repetitive supramaximal ulnar nerve stimulation during maximal weakness (A and B) and after clinical remission (C). (A) $2 \mathrm{~Hz}$ stimulation before (lower traces) and immediately after (upper traces) 5 seconds of maximal voluntary contraction. (B) $50 \mathrm{~Hz}$ stimulation. (C) $2 \mathrm{~Hz}$ stimulation before (left traces), immediately after (middle traces), and 30 seconds after (right traces) 5 seconds of maximal voluntary contraction. 


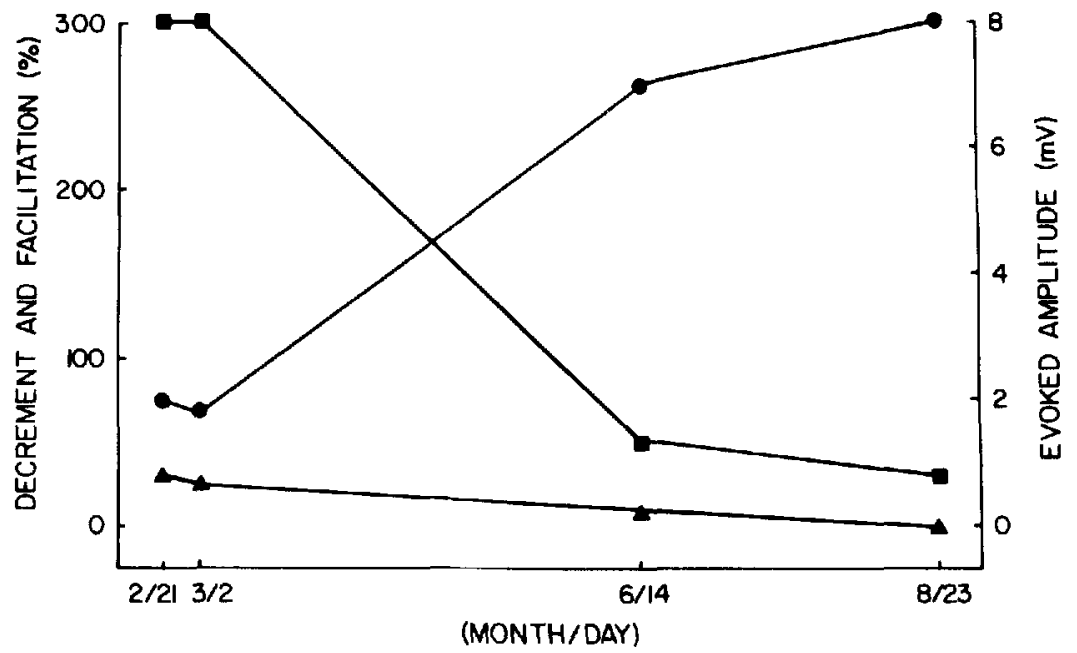

FIGURE 3. Temporal relationship of results of ulnar nerve stimulation (recorded from hypothenar muscles), demonstrating compound muscle action potential amplitude ( $\bullet$ ), maximal percentage decrement to $2 \mathrm{~Hz}$ repetitive stimulation ( $\mathbf{\Delta}$ ), and percentage facilitation immediately after 5 seconds of maximal voluntary contraction (a).

prior to onset of weakness. Aminoglycosides affect neuromuscular transmission both pre- and postsynaptically, ${ }^{23}$ but Tobramycin is least toxic. $^{3}$ Weakness has been associated with the institution of prednisone in patients with myasthenia gravis. The effects of prednisone on neuromuscular junction transmission have been studied, and both presynaptic and postsynaptic actions have been demonstrated in neuromuscular junction preparations. ${ }^{28}$ It is not known if these effects can be extrapolated to pharmacologic doses and clinical situations. In addition to direct action at the neuromuscular junction, an indirect effect has been postulated, based on varying degrees of suppression of different lymphocyte subsets at onset of prednisone therapy. 7,16 Transient increase in weakness has not been noted in LEMS in associa-

\begin{tabular}{|c|c|c|c|}
\hline \multirow[b]{2}{*}{ Test } & \multicolumn{2}{|l|}{ Date } & \multirow{2}{*}{$\begin{array}{l}\text { Normal } \\
\text { values }\end{array}$} \\
\hline & $2 / 84$ & $8 / 84$ & \\
\hline Total complement & 24 & 59 & $104-188$ units \\
\hline $\begin{array}{l}\text { C1q (Raji } \\
\text { cell assay) }\end{array}$ & 659 & NA & $0-49$ AHG eq/ML* \\
\hline $\mathrm{C} 3$ & 40 & 56 & $80-231 \mathrm{mg} \%$ \\
\hline $\mathrm{C} 4$ & 5 & 10 & $10-46 \mathrm{mg} \%$ \\
\hline ANA & $\begin{array}{c}1: 2560 \\
\text { (speckled pattern) }\end{array}$ & NA & $<1: 80$ \\
\hline $\begin{array}{l}\text { Anti-DNA } \\
\text { (Farr assay) }\end{array}$ & 69 & 23 & $0-25 \%$ \\
\hline
\end{tabular}

Note: $N A=$ not available

*Aggregated human gamma globulin equivalents. tion with institution of prednisone. Our patient had been on prednisone prior to and since her transient weakness, and in doses up to $120 \mathrm{mg} \mathrm{qD}$, without associated weakness.

The antigenic spectrum of SLE is broad. Cross reactivity of autoantibodies in SLE has been demonstrated on a monoclonal level. Hybridomas producing monoclonal antibodies reacting to denatured DNA were derived from lymphocytes of patients with SLE. Eighteen of 30 antibody lines reacted with denatured DNA and three or more additional polynucleotides. Ten of the 30 lines reacted with nucleic acids and phospholipid cardiolipin. ${ }^{22}$ In addition to activity directed to cell nucleus antigens, there is evidence for antibody activity against neuronal antigens. Sera from $75 \%$ of patients with SLE have been shown to bind with either cultured neuronal cell lines or human brain tissue. An association between antineuronal antigen binding and neuropsychiatric symptoms in SLE is an inconsistent finding. ${ }^{1}$

Our patient had supplementary immunologic evidence for a severe exacerbation of SLE. Complement levels (total complement, C3, C4) were low and were partially restored over $6-8$ months (Table 1). Skin biopsy at time of weakness showed linear deposition of all immunoglobulin classes.

The time course of onset and resolution of weakness in our patient was unusually short. In the passive humoral transfer animal model of LEMS, where the time course can be documented, animals in early studies required $30-90$ daily injections of IgG from patients with LEMS to produce electrophysiologic changes. ${ }^{15}$ Recent studies 
suggest that a more rapid time course may occur. ${ }^{12}$ The IgG serum fraction derived from two of 25 patients with LEMS produced the electrophysiologic abnormalities of LEMS in mice after a single injection. Within the first day there was a reduction in quantal release of acetylcholine which reached a plateau in 3-4 days. After 8 days recovery began, and quantal release returned to normal levels by $20-30$ days. The transient nature of our patient's weakness is thus consistent with a short-lived rise in antibody titers.

The clinical circumstances and course of our patient suggests a number of implications. The antigenic site on the presynaptic membrane in LEMS may be associated with calcium channels in the region of the active sites. ${ }^{5}$ LEMS may be explained in part by antibody cross reactivity with these sites which may occur in some patients with other autoimmune diseases. It is not known if antibody cross reactivity with brain (central nervous system) tissue antigen in patients with SLE can be extended to include peripheral nervous system tissue. The incidence of neuromuscular disorders in SLE is unknown, but only one other association of SLE and LEMS has been reported, and that patient had a long history of progressive weakness. ${ }^{8}$ The restoration of clinically normal strength in our patient before the resolution of electrodiagnostic abnormalities suggests that subclinical evidence of LEMS may exist.

\section{REFERENCES}

1. Bluestein HG, Zvaifler NJ: Antibodies reactive with central nervous system antigens. Human Pathol 14:424-428, 1983.

2. Denys EH, Day PC, Hofmann WW, Husain F: Passive transfer of the myasthenic syndrome. A preliminary report. Acta Neurol Scand (Suppl) 60:205, 1979.

3. DeRosayro M, Healy TEJ: Tobramycin and neuromuscular transmission in the rat isolated phrenic nervediaphragm preparation. Br J Anaesth 50:251-254, 1978.

4. Eaton LM, Lambert EH: Electromyography and electric stimulation of nerves in diseases of motor unit. Observations on myasthenic syndrome associated with malignant tumors. JAMA 163:1117-1124, 1957.

5. Fukunaga H, Engel AG, Osame M, Lambert EH: Paucity and disorganization of presynaptic membrane active zones in the Lambert-Eaton myasthenic syndrome. Muscle Nerve $5: 686-697,1982$.

6. Gutmann L, Crosby TW, Takamori M, Martin JD: The Eaton-Lambert syndrome and autoimmune disorders. $A m$ J Med 53:354-356, 1972.

7. Hammarstrom L, Smith E: Myasthenia gravis: steroidinduced effects on lymphocyte subpopulations in myasathenia gravis. Eur Neurol 16:16-22, 1977.

8. Hughes RL, Katirji MB: The Earon-Lambert (myasthenic) syndrome in association with systemic lupus erythematosus. Arch Neurol 43:1186-1 187, 1986.

9. Jablecki CK: AAEE Case Report \#9: Lambert-Eaton myasthenic syndrome. Muscle Nerve 7:250-257, 1984.

10. Jui-Yen T: Clinical and experimental studies on mechanism of neuromuscular blockade by chloroquine dionotate. Jpn J Anesth 20:491-503, 1971.

11. Kin YI: Passively transferred Lambert-Eaton syndrome in mice receiving purified.IgG. Muscle Nerve 9:523-530, 1986.

12. Lambert EH: Disorders of the Motor Terminal: The Lam bert-Eaton Myasthenic Syndrome. Rochester, MN, American Association of Electromyography and Electrodiagnosis AAEE Didactic Program; 1986, pp 7-8.

13. Lambert EH, Eaton LM, Rooke ED: Defect of neuromuscular conduction associated with malignant neoplasms. $A m$ J Physiol 187:612-613, 1956.

14. Lang B, Newsom-Davis J, Prior C, Wray D: Antibodies to motor nerve terminals: an electrophysiologic study of a human myasthenic syndrome transferred to mouse. I Physiol $344: 335-345,1983$.
15. Lang B, Newsom-Davis J, Wray D, Vincent A, Murray N: Autoimmune etiology for myasthenic (Eaton-Lambert) syndrome. Lancet 1:224-226, 1981.

16. Iennon VA: Immunologic mechanisms in myasthenia gravis - A model of a receptor diseasc, in Franklin EL (ed): Clinical Immunology Update. Reviews for Physicians. New York, Elsevier, 1979, pp 259-289.

17. Lennon VA, Lambert EH, Whittingham S, Fairbanks V: Autoimmunity in the Lambert-Eaton myasthenic syndrome. Muscle Nerve 5:S21-525, 1982.

18. Mackenzic AH: Pharmacologic actions of 4-aminoquinoline compounds. Am J Med (Suppl 1A):5-9, 1983.

19. Newsom-Davis J: Lambert-Eaton myasthenic syndrome. Springer Semin Immunopathol 8:129-140, 1985.

20. Newsom-Davis J, Murray NMF: Plasma exchange and immunosuppressive drug treatment in the Lambert-Eaton myasthenic syndrome. Neurology (NY) 34:480-48.5, 1984.

21. Schwartz MS, Stålberg E: Myasthenia gravis with features of the myasthenic syndrome. An investigation with electrophysiologic methods including single-fiber electromyography. Neurology (Minneap) 25:80-84, 1975.

22. Shoenfeld Y, Rauch J, Massicotte H, Datta SK, AndreSchwartz J, Stollar BD, Schwartz TS: Polyspecificity of monoclonal lupus autoantibodies produced by humanhuman hybridomas. New Engl J Med 308:414-420, 1983.

23. Singh YN, Marshall IG, Harvey AL: Depression of transmitter release and postjunctional sensitivity during neuromuscular block produced by antibiotics. $\mathrm{Br} I$ Anaesth 51:1027-1033, 1979.

24. Streib EW, Rothner AD: Eaton-Lambert myasthenic syndrome: long-term treatment of three patients with prednisone. Ann Neurol 10:448-453, 1981.

25. Tan EM, Cohen AS, Fries JF, Masi AT, McShane DJ, Rothfield NF, Schaller JG, Talal N, Winchester RJ: The 1982 revised criteria for the classification of systemic lupus erythematosus. Arthritis Rheum 25:1271-1277, 1982.

26. Vartanian GA, Chinyanga HM: The mechanism of acute neuromuscular weakness induced by chloroquine. Can $J$ Physiol Pharmacol 50:1099-1103, 1972.

27. Vroom FQ, Engel WK: Nonneoplastic steroid responsive Lambert-Eaton myasthenic syndrome. Neurology (Minneap) 19:281, 1969 .

28. Wilson RW, Ward MD, Johns TR: Corticosteroids: a direct effect at the neuromuscular junction. Neurology (Minneap) 24:1091-1095, 1974. 